\title{
Verticillium Wilt in Spinach Seed Production
}

\author{
Lindsey J. du Toit, Vegetable Seed Pathologist, Mike L. Derie, Agricultural Research Technologist, and Pablo \\ Hernandez-Perez, Graduate Student, Washington State University, Northwestern Washington REC, Mount Vernon \\ 98273-4768
}

\begin{abstract}
du Toit, L. J., Derie, M. L., and Hernandez-Perez, P. 2005. Verticillium wilt in spinach seed production. Plant Dis. 89:4-11.

There are no previous reports of Verticillium wilt in fresh and processing spinach (Spinacia oleracea) crops in the United States. In 2002, a hybrid spinach seed crop in the Pacific Northwest developed late-season wilt symptoms. Assays of the harvested seed and stock seed of the male and female parents revealed 59.5, 44.0, and 1.5\%, respectively, were infected with Verticillium dahliae. Assays of 13 stock or commercial seed lots grown in 2002 and 62 commercial lots harvested in 2003 in Denmark, Holland, New Zealand, and the United States revealed the prevalence of Verticillium spp. in commercial spinach seed. Sixty-eight lots (89\%) were infected with Verticillium spp. at incidences ranging from 0.3 to $84.8 \%$. Five spinach seed isolates of V. dahliae were pathogenic on each of three spinach cultivars by root-dip inoculation. V. dahliae was detected on $26.4 \%$ of the seed from 7 of 11 inoculated plants but on none of the seed from 6 control plants, demonstrating systemic movement of $V$. dahliae. Seed-to-seed transmission was also demonstrated by planting naturally infected seed lots. This is the first report of Verticillium wilt of spinach in the primary region of spinach seed production in the United States.
\end{abstract}

Additional keywords: Fusarium oxysporum f. sp. spinaciae, premature senescence

Spinach (Spinacia oleracea L.) seed crops grown on 1,200 to 1,600 ha in the Pacific Northwest produce up to $50 \%$ of the U.S. and world supply of spinach seed annually (9). Fusarium wilt of spinach, caused by Fusarium oxysporum Schlechtend.:Fr. f. sp. spinaciae (Sherb.) W.C. Snyder \& H.H. Hans (4), is endemic in this region and necessitates crop rotations of 6 to 15 years for seed production, depending on the susceptibility of the parent lines (9). In contrast, the only report of Verticillium dahliae Kleb. on spinach in the United States was by Snyder and Wilhelm in New York in 1962 (15), who documented seed transmission. In Holland, van der Spek $(18,19)$ demonstrated that spinach and sugar beet seed sown in soil infested with $V$. dahliae and grown to flowering produced infected seed. Furthermore, van der Spek (19) showed that $V$. dahliae could be introduced into soil by planting infested spinach seed, and that soil microflora may influence seed transmission and subsequent development of wilt symptoms. In

Corresponding author: L. J. du Toit

E-mail: dutoit@wsu.edu

Accepted for publication 14 September 2004.

DOI: 10.1094/PD-89-0004

(C) 2005 The American Phytopathological Society
Canada, Sackston and Sedun (13) achieved almost $100 \%$ infection of seed harvested from spinach plants inoculated with a Verticillium $\mathrm{sp}$.

Despite these reports of Verticillium as a pathogen of spinach, Verticillium wilt has not been observed in fresh or processing spinach crops in the United States (4), even when spinach seed is planted into fields heavily infested with $V$. dahliae from previous crops (S. T. Koike, personal communication). In 2002, a hybrid seed crop grown in western Washington developed late-season wilt symptoms, despite a 20-year rotation out of spinach in that field. Samples of the male and female stock seed (seed of the parent lines used to grow a hybrid seed crop) and the harvested seed were assayed for Fusarium, but the predominant fungus detected was Verticillium. Similarly, a high incidence of Verticillium was detected on female stock seed of a hybrid seed crop grown in western Oregon in 2002 that developed late-season wilt symptoms (L. J. du Toit, unpublished data).

The objectives of this research were to assess: (i) the prevalence of Verticillium in commercial spinach seed lots grown in the primary regions of the world in which spinach seed is produced, (ii) the pathogenicity of spinach seed isolates of $\mathrm{V}$. dahliae to spinach, and (iii) seed-to-seed transmission of Verticillium from naturally infected spinach seed. Preliminary results have been presented $(6,7)$.

\section{MATERIALS AND METHODS}

Detection of Verticillium in commercial spinach seed. Samples were collected from male and female stock seed lots and the harvested seed of a proprietary hybrid spinach seed crop grown in northwestern Washington in 2002 that displayed lateseason wilt symptoms (Cultivar F; Table 1). Samples were collected from 11 additional stock or harvested seed lots grown in Washington, Oregon, or the European Union (EU) in 2001 or 2002 (Table 1).

Each seed lot was assayed for Verticillium using a general freeze-blotter assay modified from that described by Derie et al. (5) for detection of Phoma lingam on crucifer seed. Four hundred seed per lot were either rinsed under running deionized water for $60 \mathrm{~min}$ (non-surface-sterilized assay) or soaked in $1.2 \% \mathrm{NaOCl}$ for $60 \mathrm{~s}$ and triple-rinsed in sterile deionized water (surface-sterilized assay). The seed were then dried in a laminar flow hood on sterile paper toweling. One sterile Steel blue germination blotter (8.25-cm-diameter; Anchor Paper Co., St. Paul, MN) was placed within each sterile 10 -cm-diameter plastic petri plate and moistened with $4 \mathrm{ml}$ of sterile deionized water. Using forceps that were flame-sterilized between seed, the seed were transferred onto the blotters $(20$ seed per plate) and the plates sealed with Parafilm (Pechiney Plastic Packaging, Menasha, WI). The plates were incubated in the dark at approximately $24^{\circ} \mathrm{C}$ for 24 $\mathrm{h}$ to allow the seed to imbibe. The imbibed seed were then placed at $-20^{\circ} \mathrm{C}$ for $24 \mathrm{~h}$ to kill the embryo and then transferred to an incubator (Model I30BLL, Percival Scientific, Perry, IA) set at $24^{\circ} \mathrm{C}$ with a $12 \mathrm{~h} / 12 \mathrm{~h}$ day/night cycle (nearUV and cool-white fluorescent light by day) for 12 days. The seed were examined microscopically $(\times 8$ to $\times 100$ magnification) approximately 5, 10, and 14 days after plating (Fig. 1). Verticillium and Fusarium cultures were identified to genus based on the presence of microsclerotia and/or conidiophore and conidial characteristics. A majority of the Verticillium isolates $(>90 \%)$ resembled $V$. dahliae, as the bases of the conidiophores did not darken in color with maturity and 
the isolates formed microsclerotia on pericarps of the seed and on blotters (14).

To determine whether $V$. dahliae might be eradicated from spinach seed by surface-sterilization with $\mathrm{NaOCl}$, seed of one cultivar on which Verticillium was detected at an incidence of $8.25 \%$ (Cultivar I; Table 1) was sterilized with $1.2 \% \mathrm{NaOCl}$ for 10 , 20,30 , or $40 \mathrm{~min}$ and triple-rinsed in sterile deionized water. The seed was then dried and assayed for Verticillium using the procedure described above.

In the winter/spring of 2003-04, an additional 62 spinach seed samples produced by six commercial seed companies from seed crops grown in 2003 in Denmark, Holland, New Zealand, or the United States (Table 2) were assayed using the surface-sterilization procedure described above. Analyses of variance (ANOVAs) and means comparisons were calculated by country and seed company for incidence of Verticillium, using seed lots as replications (weighted to account for different numbers of seed lots per country and company). Log transformations were used to generate normal residuals and homogeneous variances for parametric statistical analyses.

Pathogenicity of spinach seed isolates of $\boldsymbol{V}$. dahliae. In the winter of 2002-03, five isolates of $V$. dahliae obtained from five spinach seed lots were tested in the greenhouse for pathogenicity on each of three spinach cultivars: J (a smooth leaf, medium-long standing, proprietary female inbred susceptible to Fusarium wilt), E (a smooth leaf, medium standing, proprietary female inbred partially resistant to Fusarium wilt; the same cultivar listed in Table
1), and 'Winter Bloomsdale' (a true Savoy, medium-long standing, open-pollinated cultivar susceptible to Fusarium wilt) (Table 3). A sample of 400 seed of each cultivar was assayed for Verticillium using the freeze-blotter assay described above. Isolates 1 to 4 of $V$. dahliae were from seed lots harvested from seed crops grown in the United States in 2001 or 2002, and isolate 5 was from a stock seed lot grown in Holland in 2001. A randomized complete block design with four replications was used. Seed of each lot was planted into RediEarth potting mix (W.R. Grace \& Co., Ajax, ON, Canada) in a 76-cell plastic flat. For each replication of each isolate, the root plug of one transplant of each cultivar was wounded by manually tearing the roots. The root plug was then immersed in a spore suspension (approximately $10^{6}$ conidia per $\mathrm{ml}$ ) of the isolate for $60 \mathrm{~s}$, and transplanted into Sunshine Mix no. 1 potting mix (Sungro Horticulture, Seba Beach, AB, Canada). For the noninoculated control treatment of each cultivar, the root plug was dipped in sterile deionized water. At the time of inoculation, transplants of Cultivar $\mathbf{J}$ were 2 weeks old and those of Cultivar $\mathrm{E}$ and 'Winter Bloomsdale' were 9 weeks old. The plants were placed on a greenhouse bench with supplemental lighting (approximately 100 $\mu \mathrm{mol} / \mathrm{m}^{2} / \mathrm{s}$ ) provided by overhead lights for $8 \mathrm{~h} /$ day and monitored for wilt symptoms. Five weeks after inoculation, the duration of supplemental lighting was increased to $14 \mathrm{~h} /$ day to initiate bolting (conversion from vegetative to reproductive growth). Based on preliminary investigations into the pathogenicity of $V$. dahliae on spinach, severity of symptoms was rated 25 and 49 days after inoculation on a scale of 0 to 4 , where: $0=$ no symptoms, $1=$ red discoloration of the stem base, $2=$ interveinal chlorosis of the oldest leaves, $3=$ stunting and progression of interveinal chlorosis and necrosis up the plant, and $4=$ plant dead.

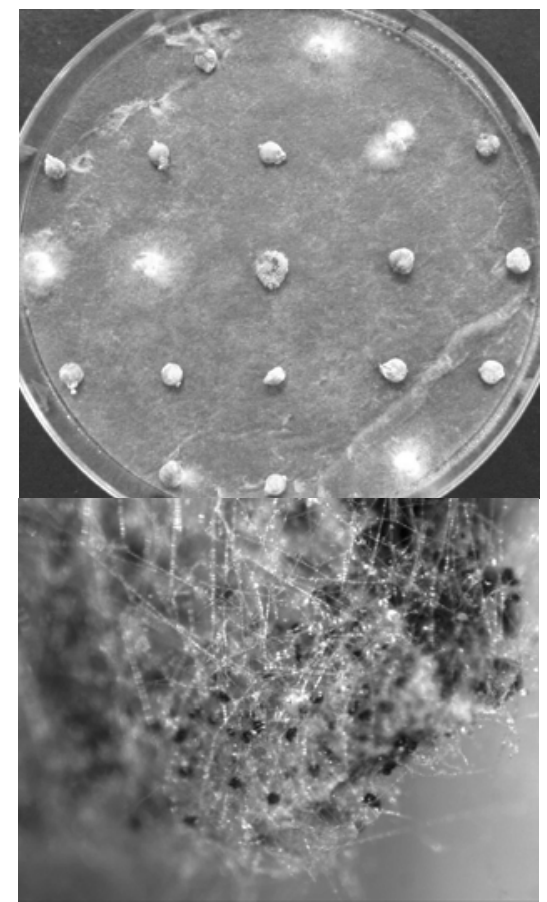

Fig. 1. Freeze-blotter assay for Verticillium on spinach seed (top), with microsclerotia and mycelium of V. dahliae on the pericarp (bottom).

Table 1. Incidence of Verticillium and Fusarium detected on spinach seed produced or planted in the United States (US) or the European Union (EU) in 2002

\begin{tabular}{|c|c|c|c|c|c|c|c|}
\hline \multirow[b]{2}{*}{$\mathrm{Cv}^{\mathrm{v}}$} & \multirow{2}{*}{$\begin{array}{c}\text { Seed } \\
\text { company }^{\mathrm{v}}\end{array}$} & \multirow{2}{*}{$\begin{array}{c}\text { Fungicide seed } \\
\text { treatment }\end{array}$} & \multirow{2}{*}{$\begin{array}{c}\text { Stock or } \\
\text { harvested seed }^{w}\end{array}$} & \multirow{2}{*}{$\begin{array}{l}\text { Region seed } \\
\text { was grown }\end{array}$} & \multirow[b]{2}{*}{ Seed treatment ${ }^{y}$} & \multicolumn{2}{|c|}{$\%$ of $\mathbf{4 0 0}$ seed $^{\mathrm{z}}$} \\
\hline & & & & & & Verticillium & Fusarium \\
\hline \multirow[t]{2}{*}{ A } & 1 & None & Harvested & EU & Rinsed & 17.00 & 1.00 \\
\hline & 2 & Thiram & Harvested & EU & Rinsed & 0.75 & 0.00 \\
\hline B & 2 & Unknown & Harvested & EU & Rinsed & 6.25 & 0.00 \\
\hline $\mathrm{C}$ & 2 & Unknown & Harvested & EU & Rinsed & 3.00 & 0.00 \\
\hline $\mathrm{D}$ & 3 & None & Harvested & US (WA) & Rinsed & 0.00 & 0.00 \\
\hline E & 3 & None & Female stock & US (WA) & Rinsed & 0.00 & 0.00 \\
\hline \multirow[t]{3}{*}{$\mathrm{F}$} & 4 & Unknown & Female stock & EU & Rinsed + sterilized & 1.50 & 0.00 \\
\hline & 4 & Unknown & Male stock & EU & Rinsed + sterilized & 44.00 & 27.75 \\
\hline & 4 & None & Harvested & US (WA) & Rinsed & 59.50 & 3.75 \\
\hline \multirow[t]{3}{*}{ G } & 4 & Unknown & Female stock & EU & Rinsed + sterilized & 11.25 & 0.00 \\
\hline & 4 & Unknown & Male stock & EU & Rinsed + sterilized & 6.50 & 0.00 \\
\hline & 4 & None & Harvested & US (WA) & Rinsed & 74.75 & 0.00 \\
\hline \multirow[t]{2}{*}{$\mathrm{H}$} & 5 & Unknown & Female stock & US (OR) & Rinsed & 35.25 & 0.00 \\
\hline & & & & & Sterilized & 26.25 & 0.00 \\
\hline \multirow[t]{5}{*}{ I } & 6 & None & Harvested & US (WA) & Rinsed & 8.25 & - \\
\hline & & & & & Sterilized $(10 \mathrm{~min})$ & 1.75 & - \\
\hline & & & & & Sterilized $(20 \mathrm{~min})$ & 0.75 & - \\
\hline & & & & & Sterilized $(30 \mathrm{~min})$ & 0.75 & - \\
\hline & & & & & Sterilized (40 min) & 0.50 & - \\
\hline
\end{tabular}

\footnotetext{
${ }^{v}$ Cultivar (cv.) and seed company identities are coded for proprietary purposes. All cultivars are smooth leaf hybrids, except 'D' which is a true Savoy, open pollinated cultivar. All cultivars are grown for fresh markets (baby leaf and bunching markets), except ' $\mathrm{D}$ ' which is for home garden markets. Cultivars $\mathrm{F}$ and $\mathrm{G}$ are also grown for processing markets. All cultivars are medium to long standing.

${ }^{\mathrm{w}}$ Male and female stock seed = seed of male and female parent lines, respectively, used to produce a hybrid seed crop. Harvested seed $=$ seed harvested from a seed crop for commercial markets.

${ }^{x}$ Seed produced in the EU (Denmark or Holland) or US (western Washington [WA] or Oregon [OR]).

${ }^{\mathrm{y}}$ Rinsed $=$ seed washed under running deionized water for $60 \mathrm{~min}$, dried, and plated onto damp sterile blotters in petri plates. Surface-sterilized $=$ seed soaked in $1.2 \% \mathrm{NaOCl}$ for $60 \mathrm{~s}$ (unless stated otherwise), triple-rinsed in sterile deionized water, dried, and plated as described for the rinsed seed.

${ }^{\mathrm{z}}$ Seed examined microscopically ( $\times 8$ to $\times 100$ magnification) approximately 5,10 , and 14 days after plating. $-=$ incidence not recorded.
} 
Forty-nine days after inoculation, the roots and stems of each plant in the first replication of the trial were washed, cut to assess vascular discoloration, incubated for 5 days on paper toweling moistened with $0.1 \% \mathrm{NaOCl}$, and examined microscopi- cally for the presence of $V$. dahliae. Prior to placing the plants on damp paper toweling, root and stem sections (approximately $5 \mathrm{~mm}^{3}$ ) were cut from each plant, surfacesterilized for $5 \mathrm{~min}$, triple-rinsed in sterile deionized water, dried on sterile paper

Table 2. Incidence of Verticillium detected on 62 spinach seed samples produced by five seed companies in four countries in 2003

\begin{tabular}{|c|c|c|c|c|}
\hline \multirow{2}{*}{$\begin{array}{l}\text { Country or } \\
\text { seed company }\end{array}$} & \multirow{2}{*}{$\begin{array}{l}\text { Seed lots infected/ } \\
\text { lots assayed }^{\mathrm{x}}\end{array}$} & \multicolumn{3}{|c|}{ Incidence $(\%)$ of seedborne Verticillium ${ }^{y}$} \\
\hline & & $\operatorname{Mean}^{\mathrm{z}}$ & Range & Median \\
\hline \multicolumn{5}{|l|}{ Country } \\
\hline Denmark & $25 / 27$ & $8.78 \mathrm{a}$ & $0.00-84.75$ & 3.25 \\
\hline Netherlands & $6 / 6$ & $26.33 \mathrm{ab}$ & $2.00-83.00$ & 22.00 \\
\hline New Zealand & $0 / 1$ & $0.00 \mathrm{a}$ & 0.00 & 0.00 \\
\hline U.S. & $26 / 28$ & $26.88 \mathrm{~b}$ & $0.00-75.25$ & 25.38 \\
\hline \multicolumn{5}{|l|}{ Company } \\
\hline 1 & $22 / 23$ & $28.66 \mathrm{~b}$ & $0.00-75.25$ & 24.50 \\
\hline 2 & $4 / 5$ & $18.05 \mathrm{a}$ & $0.00-84.75$ & 0.25 \\
\hline 3 & $22 / 24$ & $5.89 \mathrm{a}$ & $0.00-19.00$ & 3.13 \\
\hline 4 & $4 / 4$ & $34.25 \mathrm{~b}$ & $2.00-83.00$ & 26.00 \\
\hline 5 & $2 / 3$ & $9.25 \mathrm{a}$ & $0.00-25.75$ & 2.00 \\
\hline 6 & $3 / 3$ & $30.75 \mathrm{~b}$ & $28.00-36.00$ & 28.25 \\
\hline Total & $57 / 62$ & 18.51 & $0.00-84.75$ & 8.00 \\
\hline
\end{tabular}

${ }^{\mathrm{w}}$ Identities of seed companies are coded for proprietary purposes and do not necessarily correspond to codes used for companies listed in Table 1.

${ }^{x}$ All seed lots were harvested from seed crops grown in 2003. A total of 62 lots were assayed.

${ }^{y}$ Four hundred seed assayed per seed lot. All seed was surface-sterilized in $1.2 \% \mathrm{NaOCl}$ for $60 \mathrm{~s}$, triple-rinsed in sterile deionized water, dried, plated onto damp sterile blotters in 10-cm-diameter petri plates, and examined microscopically approximately 5,10 , and 14 days after plating.

${ }^{2}$ Means comparisons based on weighted analyses of variance by country and by company, with seed lots as replications. Log transformation used to generate normal residuals and homogeneous variances. Country means followed by the same letter are not significantly different based on Fisher's protected least significant difference $(P<0.05)$; similarly for company means. toweling, and plated onto Difco potato dextrose agar (PDA; Becton, Dickinson and Co., Sparks, MD) acidified with 4 drops of $85 \%$ lactic acid per liter of agar. Seed was harvested from female plants that survived and set seed. The harvested seed was assayed for Verticillium without surface-sterilization, as described above. Because incubation of plants in the moist chamber gave the same results as isolations onto PDA for the first replication, the moist chamber incubation procedure was repeated 56 days after inoculation for each plant in the second replication and 63 days after inoculation for each plant in the third and fourth replications.

The pathogenicity test was repeated in the winter of 2003-04 with slight modifications. The root plugs of 6-week-old seedlings of cultivars $\mathrm{J}$, E, and 'Winter Bloomsdale' were inoculated with spore suspensions of the five isolates of $V$. dahliae used in the previous assay, or soaked in sterile deionized water (control treatment) as described above. Two weeks after inoculation, the duration of greenhouse lighting was increased from 8 to $14 \mathrm{~h}$ /day to initiate bolting. Plants were rated for incidence and severity of wilt symptoms 22 and 53 days after inoculation. The root system of each plant was washed 59,67 , and 72 days after inoculation for the first, second, and third and fourth replications, respectively. A new pair of latex gloves

Table 3. Pathogenicity of five spinach seed isolates of Verticillium dahliae inoculated onto each of three spinach cultivars

\begin{tabular}{|c|c|c|c|c|c|c|c|c|c|c|c|c|c|}
\hline \multirow{3}{*}{$\begin{array}{l}\text { Cultivar } \\
\text { or isolate }^{u}\end{array}$} & \multicolumn{7}{|c|}{ Trial 1 (winter 2002-03) } & \multicolumn{6}{|c|}{ Trial 2 (winter 2003-04) } \\
\hline & \multicolumn{2}{|c|}{$\begin{array}{l}\text { Symptomatic } \\
\text { plants }(\%)^{\mathrm{v}}\end{array}$} & \multicolumn{2}{|c|}{ Severity of wilt ${ }^{w}$} & \multirow{2}{*}{$\begin{array}{c}\text { Root rot/ } \\
\text { vasc. disc. } \\
(\%)^{\mathrm{x}}\end{array}$} & \multirow{2}{*}{$\begin{array}{l}\text { Reiso- } \\
\text { lated or } \\
\text { obsvd. }^{x}\end{array}$} & \multirow{2}{*}{$\begin{array}{c}\text { Infested } \\
\text { seed }(\%) \\
(\text { plants) }\end{array}$} & \multicolumn{2}{|c|}{$\begin{array}{l}\text { Symptomatic } \\
\text { plants }(\%)^{\mathrm{v}}\end{array}$} & \multicolumn{2}{|c|}{ Severity of wilt ${ }^{w}$} & \multirow{2}{*}{$\begin{array}{l}\text { Root rot/ } \\
\text { vasc. disc. } \\
(\%)^{\mathrm{x}}\end{array}$} & \multirow{2}{*}{$\begin{array}{l}\text { Reiso- } \\
\text { lated or } \\
\text { obsvd. }\end{array}$} \\
\hline & 25 & 49 & 25 & 49 & & & & 22 & 53 & 22 & 53 & & \\
\hline \multicolumn{14}{|l|}{ Cultivar } \\
\hline $\begin{array}{l}\text { 'Winter } \\
\text { Blooms- } \\
\text { dale' }\end{array}$ & $85.0 \mathrm{a}^{\mathrm{z}}$ & $100.0 \mathrm{a}$ & $0.9 \mathrm{a}$ & $2.4 \mathrm{a}$ & $90.0 \mathrm{a}$ & $100.0 \mathrm{a}$ & $33.3(6)$ & $100.0 \mathrm{a}$ & $100.0 \mathrm{a}$ & $2.3 \mathrm{a}$ & $3.8 \mathrm{a}$ & $87.5 \mathrm{a}$ & $100.0 \mathrm{a}$ \\
\hline $\mathrm{E}$ & $45.0 \mathrm{~b}$ & $100.0 \mathrm{a}$ & $0.5 \mathrm{~b}$ & $2.5 \mathrm{a}$ & $100.0 \mathrm{a}$ & $100.0 \mathrm{a}$ & $28.0(10)$ & $70.0 \mathrm{~b}$ & $90.0 \mathrm{a}$ & $1.6 \mathrm{a}$ & $3.0 \mathrm{~b}$ & $79.2 \mathrm{a}$ & $100.0 \mathrm{a}$ \\
\hline $\mathrm{J}$ & $5.0 \mathrm{c}$ & $50.0 \mathrm{~b}$ & $0.1 \mathrm{c}$ & $0.6 \mathrm{~b}$ & $25.0 \mathrm{~b}$ & $80.0 \mathrm{~b}$ & $0.0(1)$ & $40.0 \mathrm{c}$ & $85.0 \mathrm{a}$ & $0.6 \mathrm{~b}$ & $2.7 \mathrm{~b}$ & $69.6 \mathrm{a}$ & $100.0 \mathrm{a}$ \\
\hline \multicolumn{14}{|l|}{ Isolate } \\
\hline 1 & $66.7 \mathrm{a}$ & $75.0 \mathrm{a}$ & $0.7 \mathrm{a}$ & $2.1 \mathrm{a}$ & $75.0 \mathrm{ab}$ & $91.7 \mathrm{a}$ & 72.7 (2) & $83.3 \mathrm{a}$ & $91.7 \mathrm{a}$ & $1.9 \mathrm{a}$ & $3.5 \mathrm{a}$ & $100.0 \mathrm{a}$ & $100.0 \mathrm{a}$ \\
\hline 2 & $41.7 \mathrm{a}$ & $75.0 \mathrm{a}$ & $0.4 \mathrm{ab}$ & $1.4 \mathrm{a}$ & $66.7 \mathrm{ab}$ & $83.3 \mathrm{a}$ & $2.9(1)$ & $75.0 \mathrm{a}$ & $100.0 \mathrm{a}$ & $1.6 \mathrm{a}$ & $3.3 \mathrm{a}$ & $92.0 \mathrm{a}$ & $100.0 \mathrm{a}$ \\
\hline 3 & $58.3 \mathrm{a}$ & $91.7 \mathrm{a}$ & $0.6 \mathrm{ab}$ & $1.9 \mathrm{a}$ & $75.0 \mathrm{ab}$ & $100.0 \mathrm{a}$ & $34.3(3)$ & $50.0 \mathrm{a}$ & $66.7 \mathrm{~b}$ & $1.0 \mathrm{a}$ & $2.0 \mathrm{c}$ & $66.7 \mathrm{~b}$ & $100.0 \mathrm{a}$ \\
\hline 4 & $33.3 \mathrm{a}$ & $83.3 \mathrm{a}$ & $0.3 a b c$ & $1.5 \mathrm{a}$ & $58.3 \mathrm{~b}$ & $100.0 \mathrm{a}$ & $19.5(4)$ & $58.3 \mathrm{a}$ & $100.0 \mathrm{a}$ & $1.1 \mathrm{a}$ & $3.0 \mathrm{bc}$ & $100.0 \mathrm{a}$ & $100.0 \mathrm{a}$ \\
\hline 5 & $25.0 \mathrm{a}$ & $91.7 \mathrm{a}$ & $0.3 \mathrm{bc}$ & $2.1 \mathrm{a}$ & $83.3 \mathrm{a}$ & $91.7 \mathrm{a}$ & $0.0(1)$ & $83.3 \mathrm{a}$ & $100.0 \mathrm{a}$ & $1.8 \mathrm{a}$ & $3.8 \mathrm{a}$ & $100.0 \mathrm{a}$ & $100.0 \mathrm{a}$ \\
\hline Control & 0.0 & 0.0 & $0.0 \mathrm{c}$ & $0.0 \mathrm{~b}$ & 0.0 & 16.7 & $0.0(6)$ & 0.0 & 41.7 & $0.0 \mathrm{~b}$ & $0.4 \mathrm{~d}$ & 17.0 & 8.3 \\
\hline
\end{tabular}

" All isolates of $V$. dahliae were obtained from spinach seed. Root plugs of each of four seedlings (replications) per cultivar were soaked in a spore suspension of the appropriate isolate (or in water for the control treatment), transplanted, and monitored for wilt symptoms. Seedlings of cultivars J, E, and 'Winter Bloomsdale' were 2, 9, and 9 weeks old at time of inoculation for trial 1, and 6 weeks old at inoculation for trial 2.

${ }^{\vee}$ Incidence (\% of four plants) with wilt symptoms at different days after inoculation.

${ }^{\mathrm{w}}$ Severity of wilt symptoms at different days after inoculation rated on a scale of 0 to 4 , where: $0=$ no symptoms, $1=$ red discoloration of the lower stem, 2 $=$ interveinal chlorosis of the oldest leaves, $3=$ stunting with interveinal chlorosis and necrosis progressing up the plant, and $4=$ plant dead.

$x \%$ of plants with root rot or vascular discoloration. Plants were washed, surface-sterilized in $\mathrm{NaOCl}$, rinsed, cut lengthwise through the stem/root to assess vascular and root discoloration, incubated in a moist chamber, and examined for $V$. dahliae. Plants were processed 49, 56, and 63 days after inoculation for the first, second, and third and fourth replications in trial 1; and 59, 67, and 72 days after inoculation for the first, second, and third and fourth replications in trial 2 , respectively.

${ }^{y}$ Seed harvested from female plants that survived and set seed were assayed for $V$. dahliae using a modified freeze-blotter assay. Analyses of variance (ANOVAs) and means separations could not be calculated because of the limited number of plants that set seed and because plants did not set seed in each cultivar-by-isolate treatment combination. Seed had not developed on plants in Trial 2 at the time plants were washed and processed.

${ }^{\mathrm{z}}$ Numbers followed by the same letter within a column are not significantly different based on Fisher's protected least significant difference $(P<0.05)$. Means comparisons were calculated separately for the main effects of spinach cultivar and isolate of $V$. dahliae. Except for wilt severity ratings, noninoculated control treatments were not included in ANOVAs and means comparisons to avoid violating assumptions of parametric statistical analyses. Mean wilt severity ratings are presented, but means separations were based on Friedman's nonparametric rank test because of the qualitative wilt severity scale. 
was worn for washing each plant to avoid transferring $V$. dahliae propagules between plants. Each plant was assessed for root discoloration, soaked in $0.5 \% \mathrm{NaOCl}$ for 5 min, rinsed under running deionized water, sliced lengthwise through the roots and stem using a knife sterilized with $70 \%$ ethyl alcohol between plants, and incubated for 5 days on paper toweling dampened with $0.1 \% \mathrm{NaOCl}$. Each plant was then examined microscopically $(\times 8$ to $\times 100$ magnification) for development of $V$. dahliae conidiophores and/or microsclerotia on the roots, crowns, and/or stems. Seed had not developed on any of the plants by the time the roots were washed, so seed assays were not carried out for the 2003-04 pathogenicity test.

ANOVAs and Fisher's protected least significant differences (LSDs) were calculated using SAS Version 8.0 (SAS Institute, Inc., Cary, NC). Except for wilt severity ratings, noninoculated control treatments were not included in the ANOVAs and means separations to avoid violating assumptions of parametric statistical analyses. Friedman's nonparametric rank ANOVAs and means separations were used for wilt severity ratings because of the qualitative severity scale.

Cultures of the five isolates of $V$. dahliae tested for pathogenicity were sent to Randy Rowe and Medani Omer at the Ohio State University to determine the vegetative compatibility group (VCG) of each isolate. Nitrate-nonutilizing mutants were generated on chlorate medium for the spinach isolates as well as each of two tester strains of VCG1, 2a, 2b, 3, 4a, and $4 \mathrm{~b}(8,11)$. The phenotypes of the nit mutants were determined by growing the mutants on media amended with different nitrogen sources. Nit1 mutants (unable to utilize nitrate but able to utilize hypoxanthine as a nitrogen source) and nitM mutants (unable to utilize nitrate or hypoxanthine) of the spinach isolates and the tester strains were paired on minimal media to determine the vegetative compatibility groups of the spinach isolates. The five isolates were also sent to Jim
Correll at the University of Arkansas for VCG testing.

Seed transmission of Verticillium. In February 2003, seed of each of four spinach cultivars, 'Winter Bloomsdale' and proprietary cultivars $\mathrm{H}, \mathrm{F}$, and $\mathrm{G}$, with 0.0 , $35.3,59.5$, and $74.8 \%$ incidence of seedborne Verticillium, respectively (Tables 1 and 4), were planted into RediEarth potting mix in a 76-cell flat ( 2 seeds per cell). Approximately 1 month after planting, each seedling plug was transplanted into a 10 -cm-diameter pot. A majority of the pots contained two plants, as both seeds germinated in most of the cells prior to transplanting. Latex gloves were worn by people handling the seedlings, and the gloves and bench surfaces were sterilized with $70 \%$ ethyl alcohol between plugs to avoid transferring Verticillium propagules between plants. The plants were maintained on a greenhouse bench with lights set at 14 $\mathrm{h} /$ day to promote bolting, and were monitored for wilt symptoms. Given the dioecious nature of spinach, male plants of 'Winter Bloomsdale' were used to pollinate female flowers of the cultivars F, G, and $\mathrm{H}$ for seed to develop. In May 2003, the roots, crown, and stem of three plants of each of cultivars $F$ and $G$ with symptoms suggestive of Verticillium wilt, one plant of cultivar $\mathrm{G}$ with symptoms typical of Fusarium wilt, and two healthy (nonwilting) plants of each of cultivars F, G, and $\mathrm{H}$ were washed thoroughly under running tap water. Each plant was then surface-sterilized for $5 \mathrm{~min}$ in $0.6 \% \mathrm{NaOCl}$, rinsed three times in sterile deionized water, and $5 \mathrm{~mm}^{3}$ sections of the roots, crown, and stem were plated onto Sorensen's NP-10 agar medium (16) and halfstrength PDA amended with streptomycin (100 ppm). In June and July 2003, seed was harvested from each female plant that had survived and set seed. One hundred seed collected from each of 5, 18, 19, and 47 plants selected randomly from 'Winter Bloomsdale' and cultivars F, G, and $\mathrm{H}$, respectively, were assayed for Verticillium using the non-surface-sterilized freezeblotter assay (Table 4).

\section{RESULTS}

Detection of Verticillium in commercial spinach seed. The incidence of seedborne Verticillium in the male and female stock seed and the harvested seed of Cultivar $F$ (the crop that developed late-season wilt symptoms in western Washington in 2002) was $44.0,1.5$, and $59.5 \%$, respectively (Table 1). The isolates produced microsclerotia on the pericarps of the seed and were identified as $V$. dahliae. In contrast, the incidence of seedborne Fusarium was $27.8,0.0$, and $3.8 \%$, respectively. Of 11 additional seed lots assayed in 2002, eight were infected with Verticillium at incidences ranging from 0.8 to $74.8 \%$, and one was infected with Fusarium at an incidence of $1.0 \%$ (Table 1). Ten-minute surface-sterilization of the seed of Cultivar I in $1.2 \% \mathrm{NaOCl}$ reduced the incidence of seedborne Verticillium detected to $1.8 \%$ compared with $8.3 \%$ on nonsterilized seed. Sterilization of the seed for up to $40 \mathrm{~min}$ did not eradicate Verticillium but reduced its incidence to $0.5 \%$ (Table 1). Microsclerotia characteristic of $V$. dahliae were observed on the pericarps of a majority of the infected seed (Fig. 1) and sometimes developed on the blue blotter around the infected seed. The bases of the conidiophores did not darken in color with maturity, indicating the isolates were not V. alboatrum (14).

The incidence of Verticillium detected on 62 spinach seed lots harvested in 2003 ranged from 0.0 to $84.8 \%$ with a mean \pm standard deviation of $18.5 \pm 22.6 \%$ infected seed per lot and a median of 8.0 infected seed per lot (Table 2). Although the highest incidence of Verticillium was detected on a seed lot grown in Denmark, the mean incidence of Verticillium was highest for seed lots grown in the United States $(26.9 \%)$ and the Netherlands (26.3\%), followed by Denmark (8.8\%). Similarly, the median incidence of infected seed per lot was highest for the United States and the Netherlands (25.4 and $22.0 \%$, respectively), and lowest for Denmark $(3.25 \%)$. Verticillium was not detected in the single seed lot from New

Table 4. Incidence of wilt symptoms and seed-to-seed transmission of Verticillium for four spinach cultivars

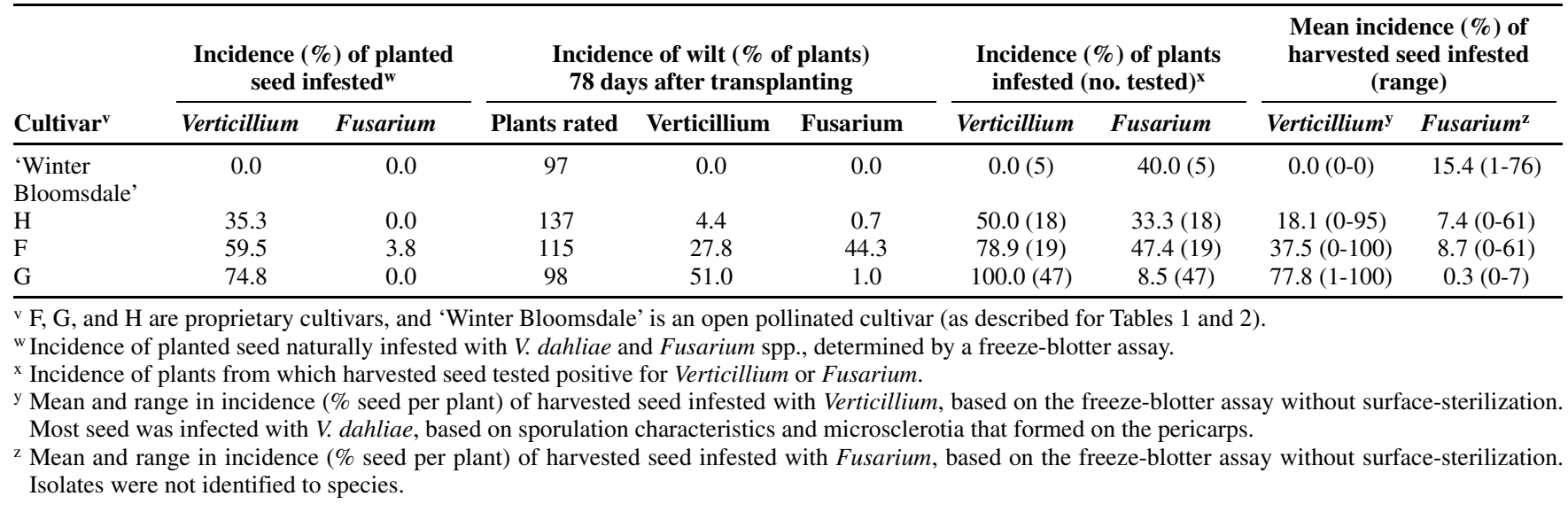


Zealand. Two seed lots from company 3; one seed lot from each of companies 1,2 , and 5; and none of the lots from companies 4 and 6 tested free of Verticillium (Table $2)$. The mean incidence of infected seed per lot was significantly lower for lots from companies 3,5 , and 2 (5.9, 9.3, and $18.1 \%$, respectively), followed by lots from companies 1,6 , and 4 (28.7, 30.8, and $34.3 \%$, respectively). The median incidence of infected seed per lot was below $10 \%$ for companies 2,3 , and $5(0.3$, 3.1 , and $2.0 \%$, respectively), and above $20 \%$ for companies 1,4 , and $6(24.5,26.0$, and $28.3 \%$, respectively).

Pathogenicity of seed isolates of $V$. dahliae on spinach. All five isolates of $V$. dahliae were pathogenic on the three spinach cultivars tested (Table 3). Results could not be pooled across the two trials because of significant interactions of the trial factor with the main effects of spinach cultivar and isolate of $V$. dahliae in the ANOVAs (data not shown). Wilt symptoms were observed primarily after bolting was initiated by increasing the duration of supplemental lighting to $14 \mathrm{~h}$ /day (i.e., when plants of cultivar $\mathbf{J}$ were 7 weeks old, and of cultivars E and 'Winter Bloomsdale' were 14 weeks old). The cultivar-byisolate interaction term of the ANOVAs was not significant for any of the dependent variables except incidence of symptomatic plants rated 53 days after inoculation in trial 2 (data not shown). In the latter case, the incidence of plants with symptoms was $100 \%$ for all but 3 of the 18 cultivar-by-isolate treatment combinations, i.e., isolate 3 on cultivars $\mathrm{J}(25 \%)$ and $\mathrm{E}$ $(75 \%)$, and isolate 1 on cultivar E $(75 \%)$. Therefore, means separations are presented in Table 3 for the main effects of spinach cultivar and isolate of $V$. dahliae.

Incidence and severity of symptomatic plants increased with maturity of the plants (Table 3). In trial 1 (2002-03), the total incidence of symptomatic plants increased from $47 \%$ (28/60 plants) to $83 \%(50 / 60$ plants) between 25 and 49 days after inoculation, respectively; similarly, the incidence of wilted plants in trial 2 (2003-04) increased from $50 \%$ (30/60 plants) to $87 \%$ (52/60 plants) between 22 and 53 days after inoculation, respectively. In each trial, the incidence and severity of symptomatic plants at the first rating was highest for 'Winter Bloomsdale' followed by cultivars $\mathrm{E}$ and $\mathrm{J}$ (Table 3 ). These differences among cultivars were less significant at the second rating in both trials. Although cultivar $\mathbf{J}$ had the lowest incidence of root rot and vascular discoloration, and the lowest incidence of $V$. dahliae reisolated or observed on plants in moist chamber, plants of this cultivar were 7 weeks younger than those of 'Winter Bloomsdale' and cultivar $\mathrm{E}$ in trial 1. In trial 2, in which plants of all three cultivars were the same age at the time of inoculation, cultivars $\mathrm{E}$ and $\mathrm{J}$ were similarly susceptible to $V$. dahliae at the second rating (Table 3 ).

The incidence of symptomatic plants was not significantly different among isolates of $V$. dahliae at 25 or 49 days after inoculation in trial 1 , nor at 22 days after inoculation in trial 2 (Table 3). By 53 days

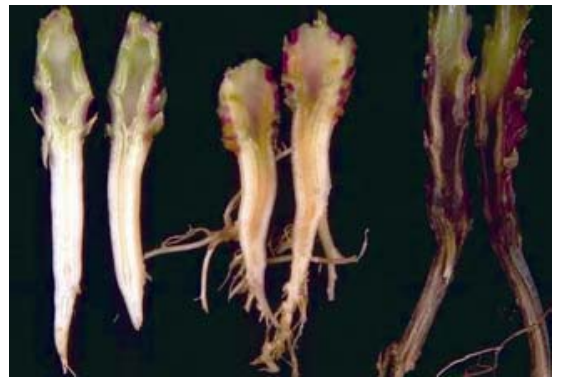

Fig. 3. Longitudinal section of the roots and crown of a healthy spinach plant (left), a spinach plant infected with Verticillium dahliae (center, showing pale brown discoloration), and a spinach plant infected with Fusarium oxysporum f. sp. spinaciae (right, showing dark brown to black discoloration). after inoculation in trial 2, the incidence of symptomatic plants was significantly less for isolate 3 than for the other four isolates. Similarly, the incidence of plants with root rot or vascular discoloration was significantly less for isolate 3 than for the other isolates of $V$. dahliae at the time the plants were processed. In trial 1, small but significant differences in wilt severity ratings were observed among isolates of $V$. dahliae 25 days after inoculation, but not by 49 days after inoculation (Table 3 ). In contrast, 22 days after inoculation in trial 2 , there were no significant differences in severity of wilt among isolates, but by 53 days after inoculation, isolates 1,2 , and 5 had caused significantly more severe wilting than isolates 3 and 4 . Mild symptoms (severity rating of 1 ) were observed on a few control plants in trial 2 by 53 days after inoculation.

Root rot and pale brown discoloration of the vascular tissues in the roots, crown,

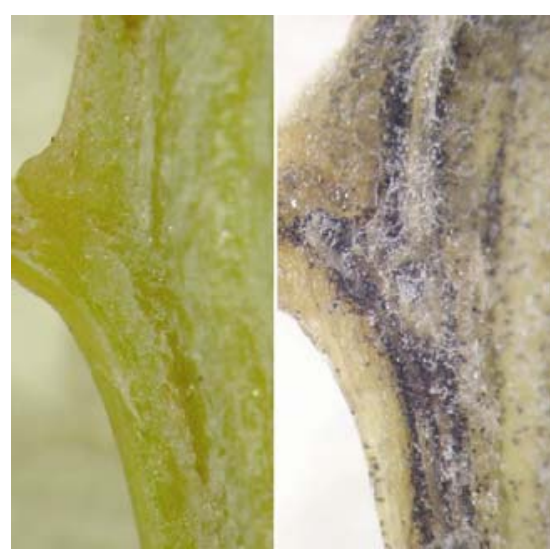

Fig. 4. Longitudinal section of the stem of a spinach plant not inoculated (left) or inoculated (right) with Verticillium dahliae by dipping the root plug in a spore suspension of the fungus prior to transplanting. Note abundant microsclerotia in the vascular tissue of the inoculated plant, observed 5 days after incubation of the inoculated plant in a moist chamber following surface-sterilization in $0.5 \% \mathrm{NaOCl}$ for $5 \mathrm{~min}$.
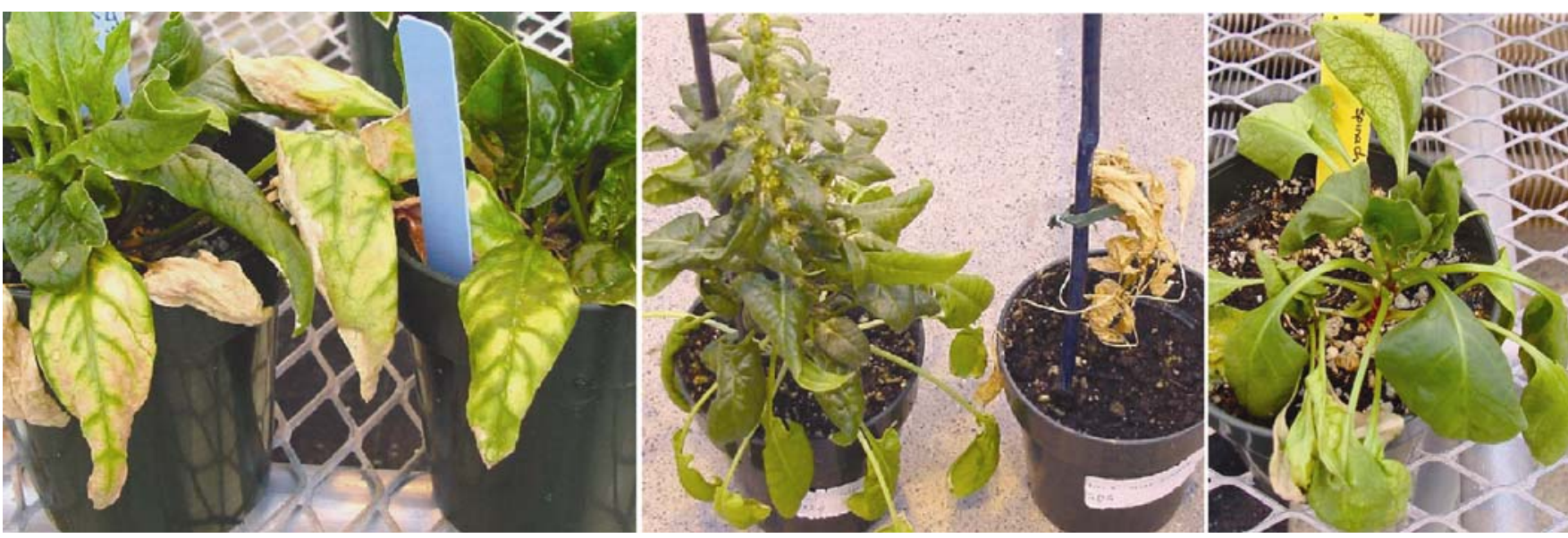

Fig. 2. Symptoms of Verticillium wilt of spinach after early initiation of bolting (left) and seed set (center: left plant noninoculated, right plant inoculated) resulting from seed transmission of Verticillium dahliae, and symptoms of Fusarium wilt of spinach (right) resulting from seed transmission of Fusarium oxysporum f. sp. spinaciae. Note the interveinal chlorosis and wilting of the oldest leaves on plants infected with Verticillium wilt versus general wilting of the entire plant and a lack of distinct interveinal chlorosis on the oldest leaves for the plant infected with Fusarium wilt. 
and lower stem were observed on $88 \%$ $(53 / 60)$ and $92 \%(55 / 60)$ of the inoculated plants in trials 1 and 2 , respectively, but on none $(0 / 12)$ of the noninoculated plants in trial 1 , and on $17 \%(2 / 12)$ of the noninoculated plants in trial 2 (Table 3). V. dahliae was reisolated from the roots, crowns, and stems (or spores and microsclerotia were observed in moist chamber) on $95 \%$ $(57 / 60)$ and $100 \%(60 / 60)$ of the inoculated plants in trials 1 and 2, respectively. Verticillium was also reisolated from $17 \%$ $(2 / 12)$ and $8 \%(1 / 12)$ of the noninoculated plants in trials 1 and 2, respectively. This was probably the result of crosscontamination of Verticillium propagules during handling and washing of the plants, as none of the control plants displayed symptoms of Verticillium wilt in trial 1.

The first symptom observed on inoculated plants was reddening of the lower stem. This was followed by a general flaccid appearance of the lowest (oldest) leaves, which developed distinct interveinal chlorosis (Fig. 2A). Symptoms progressed up the stem of symptomatic plants, some of which were severely stunted compared with noninoculated control plants, and several died (Fig. 2B). Pale brown discoloration of the vascular cylinder in the roots and crown was observed on most inoculated plants that did not die, unlike the dark brown to black discoloration of spinach roots caused by Fusarium wilt (3) (Fig. 3). Incubation of inoculated plants in a moist chamber for 5 days led to formation of abundant microsclerotia, primarily in the vascular tissues of the stem and crown (Fig. 4), but also in the roots.

Freeze-blotter assays of 400 seed of each of cultivars $\mathrm{J}$ and $\mathrm{E}$ showed that only seed of cultivar $\mathbf{J}$ was infected with Verticillium, at a low incidence of $0.25 \%(1 / 400$ seed). In contrast, assays of the seed harvested from inoculated plants showed Verticillium was present on $26 \%$ (47/178) of the seed from 7 of 11 inoculated plants that set seed in trial 1 , but on none $(0 / 205)$ of the seed from 6 control plants that set seed (Table 3). Seed harvested from plants in the third and fourth replications had the highest incidence of seedborne Verticillium per plant (up to $88 \%$, data not shown), probably reflecting the maturity of seed harvested from these plants compared with seed harvested from plants in the first two replications. An ANOVA and means comparisons could not be calculated for incidence of harvested seed infected with $V$. dahliae, as there were too many cultivarby-isolate treatment combinations in which plants did not set seed.

Vegetative compatibility grouping of the spinach seed isolates of $V$. dahliae tested for pathogenicity on spinach revealed that isolates 1 and 5 belonged to VCG $2 \mathrm{~b}$, and isolate 3 belonged to VCG $4 \mathrm{~b}$. The VCG of the remaining two isolates could not be determined by R. Rowe and M. Omer, as one isolate did not form nit mutants and the other did not pair with any known tester strains (data not shown). Correll confirmed that isolates 1 and 5 belonged to one VCG and isolates 2, 3, and 4 belonged to a second VCG, although the particular VCGs were not determined by Correll (data not shown).

Seed transmission of Verticillium. Wilt symptoms were observed on transplanted seedlings only after stem elongation (initiation of bolting), except for a few plants of cultivar $\mathrm{F}$ that, prior to bolting, developed wilt symptoms characteristic of Fusarium wilt. This was the only cultivar for which the planted seed lot tested positive for Fusarium spp. (3.8\%) (Table 4), but no attempt was made to identify the species to which these isolates belong. By 78 days after transplanting, 0.0, 5.1, 72.2, and $52.0 \%$ of the plants of 'Winter Bloomsdale' and cultivars H, F, and G had developed symptoms of wilting (Table 4). A majority of the symptomatic plants of cultivars $\mathrm{G}$ and $\mathrm{H}$ showed symptoms typical of Verticillium wilt, while $44.3 \%$ of the plants of cultivar $\mathrm{F}$ displayed symptoms typical of Fusarium wilt. Isolations from root, crown, and stem tissue of plants with either type of wilt symptom verified the association of $F$. oxysporum with general wilting symptoms and a lack of distinct interveinal chlorosis of the oldest leaves, and of Verticillium with symptoms initiated after bolting by wilting and interveinal chlorosis of the lowest leaves and acropetal progression of symptoms.

The highest incidence of plants from which Verticillium was detected on the harvested seed was for cultivar G (47/47 plants), followed by cultivars $F(15 / 19$ plants) and H (9/18 plants) (Table 4). Verticillium was not detected on any harvested seed of 'Winter Bloomsdale'. For cultivar $\mathrm{G}$, Verticillium was detected on $\geq 90 \%$ of the seed harvested from $53.2 \%(25 / 47)$ plants, and on $<10 \%$ of the seed harvested from $6.4 \%$ (3/47) plants. The incidence of plants of this cultivar on which harvested seed tested positive for Verticillium $(100.0 \%)$ was greater than the incidence of Verticillium detected on planted seed of Cultivar D (74.8\%). Similarly, the incidence of plants with infected harvested seed was greater than the incidence of plants with Verticillium wilt symptoms 78 days after transplanting (Table 4).

\section{DISCUSSION}

To our knowledge, this is the first report of $V$. dahliae as a pathogen of spinach seed crops in the Pacific Northwest, the primary region of spinach seed production in the United States. In addition, this is the first report of Verticillium wilt of spinach in the United States outside of New York since 1962, when the disease was reported by Snyder and Wilhelm (15). Despite the lack of reports of Verticillium wilt in fresh and processing spinach crops, Verticillium was found to be prevalent on commercial spinach seed lots produced in both the EU and the United States. In the initial survey of seed lots, 11 of 13 lots (84.6\%) were found to be infected with Verticillium. Subsequent assays of 62 lots harvested from spinach seed grown in 2003 revealed 57 (91.9\%) were infected with Verticillium, at incidences ranging from 0.3 to $84.8 \%$. Infected lots were detected from seed crops grown in Denmark, the Netherlands, and the United States, but not on the single lot from New Zealand. Both the number of infected seed lots and the incidence of infection of individual lots were greater than that detected by van der Spek (18), who assayed 34 spinach seed lots grown in the Netherlands in 1971 and found 20 $(58.8 \%)$ were infected with $V$. dahliae, at incidences ranging from 0.5 to $4.0 \%$.

In this study, symptoms of Verticillium wilt were not observed until after initiation of bolting, regardless of whether plants were infected by dipping the roots in a spore suspension of the pathogen or as a result of seed-to-seed transmission from naturally infected seed. The delay in development of symptoms until after bolting might explain why the disease has not been observed in fresh and processing spinach crops, which are harvested prior to bolting. To this extent, Verticillium wilt of spinach appears to be similar to Verticillium wilt of cauliflower, which is only observed in the field at the onset of "heading" (10), and Verticillium wilt of potatoes, which is commonly referred to as "early dying" (12).

Verticillium wilt symptoms followed a distinct pattern of progression on spinach plants. The first evidence of infection, observed after stem elongation, was a bright red external discoloration of the lower stem. As infection progressed, the oldest (lowest) leaves displayed interveinal chlorosis (distinct on some cultivars) which developed into interveinal necrosis. Symptoms gradually progressed up the stem, resembling premature senescence. Symptomatic plants cut lengthwise through the crown and roots typically displayed pale brown discoloration of the vascular tissue. Incubation of infected plants in a moist chamber led to formation of microsclerotia, primarily in the vascular tissues. In contrast, symptoms of infection by $F$. oxysporum f. sp. spinaciae can be observed as early as preemergence or postemergence damping-off (4). Fusarium wilt symptoms that develop after emergence include external reddening of the lower stem (similar to Verticillium wilt), followed by dark brown to black discoloration of the vascular tissue in the roots and lower stem, and general flaccid wilting of all leaves regardless of their maturity (dissimilar to Verticillium wilt). Infected plants of susceptible cultivars may die rapidly (4). Both $V$. dahliae and $F$. oxysporum f. sp. spinaciae can be seedborne 
on spinach (2). External reddening of the lower stem of spinach plants appears to be a general stress response that is not indicative specifically of Verticillium wilt or Fusarium wilt, as similar symptoms have been observed on spinach plants in response to aphid infestations and heat stress (L. J. du Toit, personal observation).

$V$. dahliae is systemic in spinach and readily seed transmitted. The high rate of seed-to-seed transmission demonstrated in this study corroborates the reports of seed transmission by other researchers $(13,15,19)$ and emphasizes the importance of using clean stock seed for spinach seed production. In the seed transmission trial, the incidence of plants from which the harvested seed was infected with Verticillium was higher than the incidence of Verticillium on planted seed. Given that two seeds were planted per pot, the higher incidence of plants with infected harvested seed may reflect movement of Verticillium between the roots of adjacent plants within a pot when only one of the planted seeds was infected. Seed-to-seed transmission was also observed on plants that did not develop obvious symptoms of Verticillium wilt, suggesting the possibility of asymptomatic infection of spinach by this pathogen. Alternatively, symptoms on these plants may have been masked as premature senescence. The resemblance of symptoms of Verticillium wilt to premature senescence may also explain why the disease has not previously been reported in spinach seed crops in the United States despite the prevalence of the pathogen in commercial seed lots.

There was no apparent relationship between the incidence of Fusarium spp. detected on the harvested seed and the incidence of plants with symptoms of Fusarium wilt (Table 4), as many of the isolates of Fusarium observed on the planted seed were species other than $F$. oxysporum (data not shown). The incidence of Fusarium wilt observed on cultivar $\mathrm{F}$ in the seed transmission trial was much greater than the incidence of Fusarium spp. detected on the planted seed (3.8\%), which suggested the freeze-blotter assay may be less effective for detecting seedborne Fusarium spp. than seedborne Verticillium spp. on spinach.

The significance of seedborne $V$. dahliae on spinach remains to be determined. Although Verticillium wilt does not appear to cause losses in fresh and processing spinach crops, the potential for the pathogen to cause losses in seed crops has been demonstrated in this study and observed in commercial seed crops in the Pacific Northwest. Furthermore, van der Spek (19) demonstrated that planting spinach seed infected with $V$. dahliae can result in infestation of the soil, which may lead to Verticillium wilt of subsequent susceptible crops planted in infested fields. Therefore, it is important to determine the specificity of the host range of isolates of Verticillium from spinach seed (3), particularly given the susceptibility of some crops (e.g., cauliflower) commonly grown in rotation with spinach in many areas of production (e.g., the Salinas Valley of California; 10).

Two of the spinach seed isolates of $V$. dahliae evaluated for pathogenicity on spinach belonged to VCG $2 \mathrm{~b}$, and one to VCG 4b. Spinach seed crops in the Pacific Northwest are commonly grown after potato crops because of the excellent weed control afforded by potato crops and the limited selection of herbicides that are not phytotoxic to spinach (9). Isolates of $V$. dahliae pathogenic to potatoes are primarily from VCG $4 a$ or VCG $4 b$ (12). If potato isolates of $V$. dahliae prove pathogenic on spinach, planting spinach seed crops following potatoes may increase disease pressure for Verticillium wilt in spinach seed crops. Therefore, the susceptibility of spinach cultivars to isolates of $V$. dahliae pathogenic on potatoes and other crops needs to be investigated. Preliminary results of ongoing research on the VCGs of a geographically diverse collection of spinach seed isolates of Verticillium indicate that all 50 isolates belong to one of two VCGs (data not shown).

Despite the lack of epidemiological knowledge on Verticillium wilt of spinach, seedborne $V$. dahliae can have a direct economic impact on the spinach seed industry because of the international nature of the seed industry and associated regulations affecting movement of seed across international borders. For example, Mexico has a phytosanitary certification requirement to prevent the import of spinach seed lots with $\geq 10 \% V$. dahliae (1). Of 62 commercial spinach seed lots grown in the United States and the EU in 2003 and assayed in this study, 30 could not have been exported to Mexico under this phytosanitary regulation. Such regulations emphasize the need for research to generate epidemiological evidence that supports, or justifies modifying, phytosanitary measures associated with seedborne Verticillium.

Research is also needed to evaluate the efficacy of physical, chemical, and biological seed treatments for control or eradication of seedborne $V$. dahliae on spinach. The thick, corky nature of the spinach pericarp, combined with the systemic infection of spinach plants by $V$. dahliae, suggests that complete eradication of $V$. dahliae from infected seed lots may be difficult. However, this study showed a reduction in incidence of seedborne Verticillium from $8.3 \%$ to $<1.0 \%$ following a 20 -min soak in $1.2 \% \mathrm{NaOCl}$, suggesting that seed treatments may effectively reduce viable seedborne inoculum below economic or phytosanitary thresholds. Increasing the duration of treatment from 20 to $40 \mathrm{~min}$ did not eradicate Verticillium, indicating that some infection was internal, as demonstrated originally by van der Spek (18).

Little is known about the variation in resistance of spinach germplasm to $V$. dahliae. Preliminary evidence from this study suggests resistance in spinach germplasm to $F$. oxysporum f. sp. spinaciae may be independent of resistance to $V$. dahliae. The availability of resistance to Verticillium wilt in commercial cultivars of other species (e.g., 12) emphasizes the potential value of screening spinach germ plasm for resistance to Verticillium wilt.

As a soilborne and seedborne pathogen that is readily seed-transmitted and highly systemic, V. dahliae poses significant hurdles for development of an integrated management plan for Verticillium wilt in spinach seed production. However, effective management practices have been developed for Verticillium wilt of other crops such as cauliflower, cotton, peppermint, potato, strawberries, and tomato (17); and these practices provide examples of efficient strategies for research efforts to increase our understanding and management of this disease in spinach.

\section{ACKNOWLEDGMENTS}

This research was supported by the Puget Sound Seed Growers' Association and the Alfred Christianson Family Endowment. The authors thank Randy Rowe and Medani Omer of the Ohio State University and Jim Correll of the University of Arkansas for assistance with determining the VCGs of spinach isolates of $V$. dahliae; seed companies for providing spinach seed samples; and Keri Berglund, Louise Brissey, Barbara Holmes, Nathan Lloyd, and Samuel Sampson for technical assistance. The project was supported by the Agricultural Research Center of the College of Agricultural, Human, and Natural Resource Sciences at Washington State University. The paper is listed as Plant Pathology New Series no. 0381.

\section{LITERATURE CITED}

1. Anonymous. 2003. International Phytosanitary Certificate No. 4051. Phytosanitary Federal Law of the Mexican United States, Phytosanitary Regulation and Inspection Department, Mexico.

2. Bassi, A., Jr., and Goode, M. J. 1978. Fusarium oxysporum $\mathrm{f}$. sp. spinaciae seedborne in spinach. Plant Dis. Rep. 62:203-205.

3. Bhat, R. G., and Subbarao, K. V. 1999. Host range specificity in Verticillium dahliae. Phytopathology 89:1218-1225.

4. Correll, J. C., Morelock, T. E., Black, M. C., Koike, S. T., Brandenberger, L. P., and Dainello, F. J. 1994. Economically important diseases of spinach. Plant Dis. 78:653-660.

5. Derie, M. L., Gabrielson, R. L., and Steen, M. 1988. Seed assays for black leg and black rot of crucifers: Working sheet for Phoma lingam Pages 19-20 in: Calif. Plant Dis. Conf. Workshop, 9-11 November 1988, California State University, Long Beach, CA.

6. du Toit, L. J., and Derie, M. L. 2003. Verticillium wilt of spinach in Washington. (Abstr.) Phytopathology 93:S22.

7. du Toit, L. J., and Derie, M. L. 2003. Verticillium wilt of spinach. Pages 20-25 in: Proc 2003 Natl. Spinach Conf., Fayetteville, AR.

8. Fiely, M. B., Correll, J. C., and Morelock, T. E. 1995. Vegetative compatibility, pathogenicity, and virulence diversity of Fusarium oxysporum recovered from spinach. Plant Dis. 79:990-993. 
9. Foss, C. R., and Jones, L. J. 2000. Crop Profile for Spinach Seed in Washington. U.S. Dep. Agric. National Pest Management Centers.

10. Koike, S. T., Subbarao, K. V., Davis, R. M., Gordon, T. R., and Hubbard, J. C. 1994. Verticillium wilt of cauliflower in California. Plant Dis. 78:1116-1121.

11. Leslie, J. F. 1993. Fungal vegetative compatibility. Annu. Rev. Phytopathol. 31:127-150.

12. Rowe, R. C., and Powelson, M. L. 2002. Potato early dying: Management challenges in a changing production environment. Plant Dis. 86:1184-1193.
13. Sackston, W. E., and Sedun, F. S. 1982. Verticillium wilt of spinach: A useful experimental system. Can. J. Plant Pathol. 4:310.

14. Smith, H. C. 1965. The morphology of Verticillium albo-atrum, V. dahliae, and V. tricorpus. N.Z. J. Agric. Res. 8:450-478.

15. Snyder, W. C., and Wilhelm, S. 1962. Seed transmission of Verticillium wilt of spinach. Phytopathology 52:365.

16. Sorensen, L. H., Schneider, A. T., and Davis, J. R. 1991. Influence of sodium polygalacturonate sources and improved recovery of Verticillium spp. from soil.
(Abstr.) Phytopathology 81:1347.

17. Tjamos, E. C., Rowe, R. C., Heale, J. B., and Fravel, D. R., eds. 2000. Advances in Verticillium Research and Disease Management. American Phytopathological Society, St. Paul, MN.

18. van der Spek, J. 1972. Internal carriage of Verticillium dahliae by seeds and its consequence. Meded. Fac. Landbouwwet. Rijksuniv. Gent 37:567-573.

19. van der Spek, J. 1973. Seed transmission of Verticillium dahliae. Meded. Fac. Landbouwwet. Rijksuniv. Gent 38:1427-1434. 